\title{
Aplicação de um programa de sustentabilidade para a coleta seletiva na cidade de São Gabriel-RS
}

\author{
The implementation of a sustainability indicator for municipal selective collection in \\ São Gabriel - RS
}

Anna Karolline Rezende dos Santos e Jefferson Marçal Rocha

Universidade Federal do Pampa, RS, Brasil

karolrezend@hotmail.com; jeffersonmrocha@gmail.com

\begin{abstract}
Resumo
Este trabalho apresenta uma proposta de aplicação de um método de indicadores para avaliação do programa municipal de coleta seletiva do município de São Gabriel, que teve início no ano de 2015. Este programa tem como base à lei de Política Nacional de Resíduos Sólidos que passou a obrigação para o poder público realizasse o gerenciamento da coleta de resíduos. Tem a perspectiva de identificar os níveis de sustentabilidade econômica, socioambiental e sanitária com base nos conceitos de gestão integrada e compartilhada, constituída no Brasil como um modelo de política pública de resíduos sólidos. Analisa o programa de coleta seletiva municipal, que é desenvolvido em parceria com uma associação de catadores. Considera-se que estudos de avaliação de programas de coleta seletiva são escassos havendo uma carência de indicadores validados para essa avaliação. Para coleta de dados utilizou-se de levantamento bibliográfico, documental referente ao tema e entrevistas com os agentes qualificados que atuam neste setor. Esta pesquisa pôs em pauta a importância de se utilizar indicadores de sustentabilidade para programas de coleta seletiva e para organização de catadores auxiliando no monitoramento do programa, propondo metas e alternativas de gestão com a perspectiva de tornar a atividade de coleta de resíduos mais sustentável.
\end{abstract}

Palavras-chave: Gestão ambiental pública. Coleta seletiva. Indicador de sustentabilidade

\begin{abstract}
This paper presents an application proposed a method of indicators to evaluate the municipal program of selective collection in the municipality of San Gabriel, which started in 2015. This program is based on the law of the National Solid Waste Policy which now obligation for the public to perform the management of waste collection. It has the prospect of identifying the levels of economic, environmental and health based on the concepts of integrated and shared management, established in Brazil as a public policy model of solid waste. Analyzes the municipal selective collection program, which is developed in partnership with a collectors association. It is considered that the selective collection program evaluation studies are lacking and there is a lack of validated indicators for this assessment. For data collection was used a literature review, document concerning the issue and interviews with qualified agents who work in this sector. This research put on the agenda the importance of using sustainability indicators for selective collection programs and collectors' organization assisting the program monitoring, proposing goals and management alternatives at the prospect of making more sustainable waste collection activity.

Keywords: Public environmental management. Selective collect. Sustainability indicator
\end{abstract}




\section{Introdução}

A gestão sustentável dos resíduos sólidos surge como uma questão socioambiental estratégica a ser enfrentado, decorrente do acelerado processo de urbanização e concentração populacional nas cidades e da produção desmedida de resíduos decorrentes dos padrões insustentáveis de produção e consumo. Com o advento da revolução industrial e a crescente urbanização, houve um aumento na concentração de pessoas nas cidades, reunindo boa parte da geração de resíduos em um único lugar. Entretanto, foi a partir da percepção que os modelos econômicos utilizados até os anos de 1960, estariam comprometendo os recursos naturais, que iniciou a utilização do termo desenvolvimento sustentável, que aliava o desenvolvimento econômico, com a preservação ambiental (ROCHA, 2011).

De acordo com Porto (2005), a crise ambiental contemporânea vem intensificando as discussões e a percepção pública acerca dos efeitos dos processos de produção e consumo das sociedades industriais pós-modernas sobre a saúde humana e a dos ecossistemas.

Os resíduos sólidos gerado nos municípios são problemas ambientais atuais e futuros. Considerada como um marco histórico da gestão ambiental no Brasil, a lei que estabelece a Política Nacional dos Resíduos Sólidos passa a estabelecer uma visão moderna contra um dos maiores problemas do planeta, o lixo urbano. Tendo como principio a responsabilidade compartilhada entre governo, empresas e população. A legislação impulsiona o retorno dos produtos às indústrias após o consumo e passa a obrigação para que o poder público realize planos para o gerenciamento do lixo. A lei também consagra o viés social da reciclagem incentivando a participação formal dos catadores organizados em cooperativas, promovendo mudanças no cenário atual dos resíduos. As legislações referentes à Política Nacional de Resíduos Sólidos (Projeto de Lei 203/91) inserem as organizações de catadores no sistema de gestão de resíduos sólidos e incentivam a implementação de programas municipais de coleta seletiva em parceria com catadores organizados. $\mathrm{Na}$ busca do desenvolvimento sustentável devem-se levar em consideração todas as formas de minimização dos resíduos, e consequentemente problemas a saúde pública e ao meio ambiente. Cabendo então, aos profissionais dessa área à conscientização de seu papel perante a sociedade, e do risco que o manejo incorreto de resíduos sólidos urbanos oferecem nos diferentes âmbitos.

Esse trabalho procura estudar um método de indicadores para avaliação do programa municipal de coleta seletiva, que teve início no ano de 2015 na cidade de São Gabriel-RS. Este programa tem como base à lei de Política Nacional de Resíduos Sólidos que passou a obrigação para o poder público realizasse o gerenciamento da coleta de resíduos. Com a perspectiva de identificar os níveis de sustentabilidade econômica, socioambiental e sanitária com base nos conceitos de gestão integrada e compartilhada, constituída no Brasil como um modelo de política pública de resíduos sólidos. Este trabalho analisa o programa de coleta seletiva municipal, que é desenvolvido em parceria com uma associação de catadores organizados.

\section{Revisão Bibliográfica}

A revisão da literatura tem como objetivo fazer uma breve contextualização dos principais temas que se relacionam com a temática deste texto, abordará os temas: Política Nacional dos Resíduos Sólidos, gestão de resíduos sólidos domiciliares na sua interface com a sustentabilidade urbana e os programas de coleta seletiva com inclusão social, além da abordagem de outros temas considerados importantes para a discussão da analise vivenciada durante a realização deste trabalho. 
2.1 Política Nacional Dos Resíduos Sólidos (Pnrs) - Lei № 12.305, De 2 De Agosto De 2010

A Política Nacional dos Resíduos Sólidos, sancionada em agosto de 2010, definiu diretrizes gerais para a gestão dos resíduos. Sua regulamentação ocorreu em dezembro de 2010, por meio de Decreto.

Esta lei estabelece os princípios, objetivos e instrumentos, assim como as diretrizes relativas à gestão integrada e ao gerenciamento de resíduos sólidos (BRASIL, 2010).

A busca pela melhoria na gestão dos resíduos fica orientada na PNRS como gestão integrada dos resíduos, no qual é definida como um conjunto de ações voltadas para a busca de soluções para os resíduos sólidos, de forma a considerar as dimensões política, econômica, ambiental, cultural e social, com controle social e sob a premissa do desenvolvimento sustentável (BRASIL, 2010).

A PNRS define como instrumentos, entre outros: o plano de resíduos sólidos, a coleta seletiva, a logística reversa, a educação ambiental, o monitoramento e a fiscalização ambiental, sanitária e agropecuária; Sistema Nacional de Informações sobre a Gestão dos Resíduos Sólidos (Sinir); e como disposições gerais, define em seu $\mathrm{Art}^{\mathrm{o}}$. 14 os planos de resíduos sólidos, como:

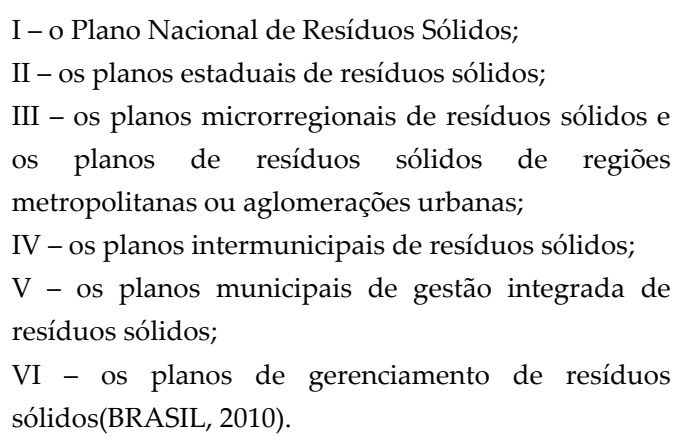

No Brasil os resíduos ganharam destaque no cenário nacional devido ao crescimento econômico do país nos últimos anos aliado ao crescimento das cidades, e da mudança de vida brasileira. A falta de gestão dos resíduos sólidos tem ocasionado impactos negativos ao meio ambiente por provocar danos ao solo, ao ar e às águas superficiais, carregando agentes poluentes presentes nos resíduos, os quais infiltram no solo e podem atingir as águas subterrâneas (AVELAR, 2006).

De acordo com a Política Nacional de Resíduos Sólidos (2010) resíduos sólidos são definidos como:

Resíduos sólidos: material, substância, objeto ou bem descartado resultante de atividades humanas em sociedade, a cuja destinação final se procede, se propõe proceder ou se está obrigado a proceder, nos estados sólido ou semissólido, bem como gases contidos em recipientes e líquidos cujas particularidades tornem inviável o seu lançamento na rede pública de esgotos ou em corpos d'água, ou exijam para isso soluções técnica ou economicamente inviáveis em face da melhor tecnologia disponível;(BRASIL, 2010).

O que se pretende com a nova política nada mais é do que a proteção da saúde pública e da qualidade ambiental, a adoção e desenvolvimento de tecnologias e práticas que causem o menor índice de impactos ambientais, a redução do volume e da periculosidade dos resíduos perigosos, a gestão integrada de resíduos sólidos entre outros.

\subsection{Coleta seletiva}

De acordo com o Art. $3^{\circ}$, inc. $\mathrm{V}$ da Lei 12.305 responsável pela política nacional de resíduos sólidos, a coleta seletiva é a coleta de resíduos sólidos previamente segregados conforme sua constituição ou composição. Pois a coleta seletiva não se constitui da separação feita após o recolhimento dos resíduos, e sim a separação feita anteriormente ao descarte. A segregação mais conhecida é feita através das categorias: resíduos inorgânicos (plásticos, papéis, metais, vidros - limpos ou lavados) e, resíduos orgânicos (restos de alimentos, cascas de frutas, ervamate, etc.). A resolução do CONAMA n 275/01 determina o padrão de cores para cada lata de lixo.

A partir do gerenciamento dos resíduos através da coleta seletiva, a organização geradora, 
dará aos seus resíduos a destinação adequada e ainda criará valores ambientais, que poderão se converter em novas fatias de mercados consumidores.

Além do objetivo principal da coleta seletiva, que é a reciclagem de materiais, deve-se trabalhar a teoria dos 3R's (Reduzir, Reutilizar e Reciclar), com a redução na geração de resíduos, no processo produtivo e principalmente nas atividades gerenciais, a cultura de reutilização de materiais na empresa e a reciclagem em si, onde o material passará por um novo processo produtivo.

Segundo o Art. $6^{\circ}$, inc. III da Lei 12.305 a visão sistêmica, na gestão dos resíduos sólidos, deve considerar as variáveis ambiental, social, cultural, econômica, tecnológica e de saúde pública.

Esta Lei ainda ressalta que a Eco-eficiência esteja presente nas organizações, mediante a compatibilização entre o fornecimento, a preços competitivos, de bens e serviços qualificados que satisfaçam as necessidades humanas e tragam qualidade de vida e a redução do impacto ambiental e do consumo de recursos naturais a um nível, no mínimo, equivalente à capacidade de sustentação estimada do planeta.

O Art. $7^{\circ}$ da mesma Lei incentiva ao desenvolvimento de sistemas de gestão ambiental e empresarial voltados para a melhoria dos processos produtivos e ao reaproveitamento dos resíduos sólidos, incluídos a recuperação e o aproveitamento energético.

Sabe-se que somente a coleta seletiva não tornará a empresa sustentável, mas poderá ser o primeiro passo para transformação de uma organização anteriormente despreocupada, para uma moderna que se adapte aos novos modos de produção e consumo, pensando nas gerações atuais e futuras.

\subsection{Coleta Seletiva municipal e a Associação de catadores Municipais Sepé Tiarajú}

A associação de catadores municipais Sepé Tiaraju desenvolve o Projeto Minuano promovido pela ONG Planeta Vivo, com apoio da Petrobrás, foi lançado em São Gabriel em fevereiro do ano de 2013. O programa vem ao encontro do decreto presidencial $\mathrm{n}^{\circ} 5940 / 2006$ que institui a separação dos resíduos recicláveis descartados pelos órgãos e entidades da administração pública federal direta e indireta, na fonte geradora, e a sua destinação às associações e cooperativas dos catadores de materiais recicláveis.

O Projeto Minuano tem atuação em 25 cidades do Rio Grande do Sul, beneficiando cerca de 800 catadores, com sede em Caxias do Sul. O objetivo é fortalecer e ampliar a rede de catadores gaúchos, impulsionando o seu protagonismo na cadeia produtiva da reciclagem e na questão ambiental, contribuindo para erradicar a miserabilidade proporcionando melhores condições de vida aos beneficiados.

Atualmente a cobertura da coleta seletiva municipal de São Gabriel acontece de segunda a sábado e seu itinerário contempla em torno de 45 bairros e algumas das principais avenidas da cidade. Segundo dados do IBGE o município de São Gabriel conta com uma população de $60.425 \mathrm{hab}$. resultando em uma coleta de 30ton./mês de resíduos recicláveis, segundo dados da presidente da associação de catadores Sepé Tiaraju.

A cadeia produtiva da reciclagem tem início com a separação dos materiais na fonte geradora, dos resíduos recicláveis, orgânicos e rejeitos. $\mathrm{O}$ processo da coleta seletiva municipal envolve o recolhimento diário dos resíduos recicláveis e posterior recolhimento para o galpão local onde acontece o processo de triagem, momento em que são separados os resíduos que serão utilizados para posterior compactação pela prensa com que tem como principal destino o comércio para empresas que tenham interesse em reciclar e produzir um novo produto ao mercado. 


\section{Método de Pesquisa}

Esta pesquisa utilizou-se como base uma ferramenta de análise denominada COSELIX, realizada na grande São Paulo e relatada em Besen e Ribeiro (2006), apresenta já definida duas matrizes conceituais distintas de sustentabilidade, uma para os programas de coleta seletiva e outra para as organizações de catadores, a partir das quais os indicadores e índices foram construídos, descritas a baixo:

1-Sustentabilidade de um programa socioambiental de coleta seletiva "é a capacidade de desenvolver suas atividades com garantia legal de recursos e com a meta de universalização dos serviços e obtenção de resultados ambientais e sociais crescentes” (Besen e Ribeiro, 2006,p.87).

2-Sustentabilidade socioeconômica e institucional das organizações "é a capacidade de desenvolver suas atividades, com a garantia de regularização institucional e a realização de trabalho e geração de renda em condições adequadas aos membros da organização" (Besen e Ribeiro, 2006,p.87).
Na pesquisa COSELIX, foram abordados um universo de variáveis que permitiu a construção dos indicadores. A base desta sistematização, a ser considerada nesta pesquisa tendo como referência a coleta de resíduos de São Gabriel, foi definida a partir da formulação conceitual de sustentabilidade, possibilitando a escolha das categorias, das variáveis, dos indicadores e o estabelecimento de suas respectivas gradações.

\section{Resultados e Discussões}

Para analisar o programa de coleta de resíduos de São Gabriel, foram selecionadas seis categorias que definiram a sustentabilidade dos programas municipais de coleta seletiva, veja abaixo:

1)Sustentabilidade econômica; 2)Marco legal; 3)Parcerias do programa de coleta seletiva; 4)Cobertura da coleta; 5)Índice de recuperação de materiais recicláveis - IRMR; 6) Índice de rejeito IR.

Para cada categoria foi definido um indicador (1 a 6$)$.

Tabela 1 - Indicadores, índices e gradações dos programas de coleta seletiva

\begin{tabular}{|c|c|c|c|}
\hline Indicador & $+($ alto) & - (baixo) & +/- (médio) \\
\hline $\begin{array}{l}\text { 1. Sustentabilidade } \\
\text { econômica }\end{array}$ & $\begin{array}{l}\text { Existência de } \\
\text { taxa específica }\end{array}$ & $\begin{array}{l}\text { Não existência de } \\
\text { cobrança }\end{array}$ & $\begin{array}{l}\text { Cobrança de taxa no } \\
\text { IPTU }\end{array}$ \\
\hline 2. Marco legal & $\begin{array}{l}\text { Com lei e } \\
\text { convênio }\end{array}$ & $\begin{array}{l}\text { Sem lei nem } \\
\text { convênio }\end{array}$ & Só lei ou só convênio \\
\hline 3. Parcerias & Duas ou mais & Nenhuma & Uma \\
\hline 4. Cobertura da coleta & $\begin{array}{l}\text { Alta }-75 \% \text { a } \\
100 \%\end{array}$ & $\begin{array}{l}\text { Baixa - menos de } \\
30 \%\end{array}$ & Média $-31 \%$ a $74,9 \%$ \\
\hline $\begin{array}{l}\text { 5. Índice de recuperação } \\
\text { de materiais } \\
\text { recicláveis - IRMR }\end{array}$ & $\begin{array}{l}\text { Alto - acima de } \\
11 \%\end{array}$ & Baixo - até 5\% & Médio - $5,1 \%$ a $10 \%$ \\
\hline 6. Índice de rejeito - IR & Baixo - até $7 \%$ & Alto - acima de $21 \%$ & Médio $-5,1 \%$ a $20 \%$ \\
\hline
\end{tabular}

. (fonte: BASEN e RIBEIRO 2006) 
A Tabela 1, abaixo, apresenta a aplicabilidade em um conjunto de indicadores e de índices de sustentabilidade para o programa de coleta seletiva municipal da cidade de São Gabriel, RS.

1- Sustentabilidade econômica: Não existe cobrança específica registrada para o programa de coleta seletiva municipal. Considerado como baixo o nível de sustentabilidade;

2- Marco legal: Existência de um contrato formalizado por meio de instrumento legal firmado com o executivo municipal com vigência de 1 ano à contar do mês de março de 2015. Considerado como médio o nível de sustentabilidade.

3- Parcerias do programa de coleta seletiva: Considerados como parceiros a prefeitura municipal, redes públicas e privada de ensino e Grupo Minuano. Salienta-se que estamos nos embasando apenas pelos documentos oficiais, não temos informações se estes convênios estão de fatos sendo executados, ou são meramente pró formas. Considerado como alto o nível de sustentabilidade.

4- Cobertura da coleta: Considerado como uma alta cobertura (89\%), abrangendo em torno de 42 bairros dos 47 existentes no município como também as principais avenidas da cidade. Considerado alto o nível de sustentabilidade;

5- Índice de recuperação de materiais recicláveis - IRMR:

Quantidade de coleta seletiva - quantidade de rejeito da triagem $\times 100$

Quantidade coletada seletivamente + quantidade da coleta regular $10,32 \%$

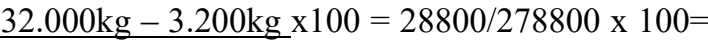

$28.800 \mathrm{~kg}+250.000 \mathrm{~kg}$

Considerado como médio o nível de recuperação de materiais recicláveis, atingindo uma porcentagem de $10,32 \%$.

6- Índice de rejeito - IR:

Quantidade de coleta seletiva - quantidade de materiais comercializados $\times 100$
Quantidade da coleta seletiva

$10 \%$

$\underline{32.000 \mathrm{~kg}-28.800 \mathrm{~kg} \times 100=32 / 32.000 \times 100=}$ $32.000 \mathrm{~kg}$

Considerado como médio o nível de rejeito, atingindo uma porcentagem de $10 \%$.

A tabela 2 apresenta os indicadores de sustentabilidade da organização de catadores, e suas respectivas gradações. Foram selecionadas 12 variáveis ou indicadores, que compuseram o conjunto representativo dos fatores que contribuíram para a sustentabilidade socioeconômica e institucional das organizações. As categorias e os indicadores são: 1) dimensão política e institucional (1 e 2) ; 2) dinâmica socioeconômica e institucional (3,4,5 e 6); 3)infraestrutura e equipamentos(7 e 8);4) condições de trabalho $(9,10$ e 11); e 5) rede de apoio das organizações (12).

1 e 2 : Regularização da organização: a associação é instituída formalmente e inserida no escopo da política pública municipal de resíduos sólidos, firmada por meio de contrato com vigência de 1 ano (a contar do mês de março de 2015) concebida sem licitação por ser a única associação de forma organizada existente no município. Considerado como alto o índice de sustentabilidade.

3: Rotatividade anual: com valores representados em $12 \%$ referente aos 2 funcionários que saíram da associação que atualmente conta com uma equipe de 16 funcionários. Considerado como alto o nível de sustentabilidade.

4: Capacitação dos membros: os associados dispõem de treinamento e capacitação oferecidos pelo próprio projeto Minuano, onde o catador tem suporte para que desempenhe as diversas atividades inerentes à coleta, segregação e posterior comercialização do materiais recicláveis. Considerado como médio o nível de sustentabilidade.

5: Renda mensal por membro: os valores variam entre um e dois salários mínimos,. Os valores estimados são: R\$ $1.200,00$ valor repassado para os 
Tabela 2 - Indicadores, e gradações das organizações de catadores

\begin{tabular}{|c|c|c|c|}
\hline Indicador & $+($ alto) & - (baixo) & +/- (médio) \\
\hline 1. Regularização da organização & Regularizada & Não regularizada & $\ldots$ \\
\hline 2. Instrumentalização legal de parceria & $\begin{array}{lr}\text { Cooperativa } & \mathrm{c} / \\
\text { convênio } & \text { ou } \\
\text { OSCIP } & \mathrm{c} / \\
\text { contrato } & \end{array}$ & Não possúi & $\begin{array}{l}\text { Associação com } \\
\text { convênio }\end{array}$ \\
\hline 3. Rotatividade anual & $\begin{array}{l}\text { Até } 25 \% \text { dos } \\
\text { membros }\end{array}$ & $\begin{array}{l}\text { Mais de } 50 \% \text { dos } \\
\text { membros }\end{array}$ & $\begin{array}{l}\text { Entre } 25 \% \text { e } 50 \% \\
\text { dos membros }\end{array}$ \\
\hline 4. Capacitação dos membros & Incubada & $\begin{array}{l}\text { Não incubada/ } \\
\text { não capacitada }\end{array}$ & Capacitada \\
\hline 5. Renda mensal por membro & $\begin{array}{l}\text { Dois salários } \\
\text { mínimos }\end{array}$ & $\begin{array}{l}\text { Um } \quad \text { salário } \\
\text { mínimo }\end{array}$ & $\begin{array}{l}\text { Entre um e dois } \\
\text { salários mínimos }\end{array}$ \\
\hline 6. Participação dos membros & alta & baixa & média \\
\hline 7. Condição da instalação & Própria & Cedida & Alugada \\
\hline 8. Equipamento/veículo & Própria & Cedida & Próprio/cedido \\
\hline 9. Horas trabalhadas dia/membro & Mais de 6 & Até 4 & Entre 4 e 6 \\
\hline 10. Benefícios para os membros & 3 ou mais & Nenhum & Um ou dois \\
\hline 11. EPI's & Usam EPI's & Não possuem & Não usam \\
\hline 12. $\mathrm{N}^{\circ}$ de parcerias das organizações & Duas ou mais & Uma & Nenhuma \\
\hline
\end{tabular}

(fonte: BASEN e RIBEIRO 2006)

motoristas do caminhão, $\mathrm{R} \$ 1.000,00$ valor repassado aos catadores que trabalham na rua e $\mathrm{R} \$ 800,00$ para os associados que trabalham na triagem do material. Considerados como médio o indicador de sustentabilidade

8: Equipamentos/veículos: o único veículo que a associação dispõe é um caminhão baú cedido temporariamente pelo período de 5 anos pelo projeto minuano. Considerado como médio o índice de sustentabilidade.

9: Horas trabalhadas dia/membro: os associados cumpres expediente de 8 horas diárias, organizadas em dois turnos de trabalho. Considerado como alto o índice de sustentabilidade.

10: Benefícios para os membros: os associados dispõem de dois benefícios, sendo um deles parte do valor repassado pela prefeitura municipal e também o MEI (Micro Empreendedor Individual) que respaldo o catador caso haja algum incidente. Considerado como um médio índice de sustentabilidade.

11: EPI's: possuem EPI's porém a maioria dos associados não usam por alegarem má adaptação. Considerado como médio o índice de sustentabilidade.

12: Número de parcerias das organizações: foram considerados 4 principais parcerias que colaboram 
com as atividades da associação. Considerado como alto o nível de sustentabilidade.

\subsection{Metodologia de composição do índice de sustentabilidade}

Esses indicadores e suas respectivas gradações levaram à composição de índice de sustentabilidade. Para tanto, considerou-se que cada valor + (mais), atribuído ao indicador em análise, valeria 1 ponto; cada valor $+/-$ (mais ou menos) valeria 0,5 pontos e cada valor - (menos) não somaria nenhum ponto. A somatória dos valores numéricos levou a um número que representa o índice de sustentabilidade do programa ou organização. A partir desse número, foi possível efetuar o atual índice do programa municipal de coleta seletivo bem como a organização de catadores (GUNTHER et al, 2007; BESEN et al, 2007).

O grau de sustentabilidade para o programa municipal de coleta seletiva foi definido como baixo o valor que compreender de 0 a 1,9 pontos; médio valores entre 2 a 3,9 pontos e alto valores entre 4 e 6 pontos.

O grau de sustentabilidade para a organização de catadores, foi definido como baixo o valor que compreender de 0 a 3,9 pontos; médio baixo valores entre 4 a 5,9 pontos; médio alto valores entre 6 a 7,9 pontos e alto valores de 8 a 12 pontos.

\section{Conclusões}

A pesquisa mostra resultados que poderá servir de apoio para que se estabeleça os níveis de sustentabilidade tanto para o programa municipal de coleta seletiva quanto para a organização de catadores municipais.

Com relação ao programa municipal de coleta seletiva o resultado mostra que não foi atingido um alto grau de sustentabilidade, totalizando 3,5 pontos atingindo um grau considerado médio.
Já com relação à sustentabilidade da organização de catadores, obteve-se o somatório de 7,5 pontos atingindo um grau médio alto de sustentabilidade.

No entanto este resultado reforça a importância de constante melhoria tanto dos programas de coleta seletiva quanto das organizações de catadores na perspectiva da sua sustentabilidade social, econômica, ambiental e sanitária.

A aplicação da pesquisa COSELIX representou um avanço na medida em que colocou em pauta a importância de utilizar índices de sustentabilidade tanto para programas de coleta seletiva como para organizações de catadores. Com uma proposta de fácil aplicação e compreensão dos resultados pode dar apoio à sua avaliação e monitoramento, podendo dar suporte para administração municipal possibilitando o aprimoramento do programa de coleta. Já para organização de catadores possibilita o planejamento e a sustentabilidade na auto-gestão.

Os resultados na aplicação do programa mostram que ainda existe uma deficiência no que se refere à sustentabilidade da coleta seletiva no município de são Gabriel. $\mathrm{O}$ alto grau de sustentabilidade pretendido ainda é uma realidade inexistente no município, considerando que a adesão à coleta seletiva se dá também pela disposição da população a esta atitude.

\section{Referências}

AVELAR, S. A. Avaliação do Sistema de Gerenciamento de Resíduos Sólidos Urbanos do Município de Coronel Fabriciano - Minas Gerais. Minas Gerais: UNEC, 2006. 113 p. Dissertação de Mestrado (Programa de Pós-graduação Meio Ambiente e Sustentabilidade). Centro Universitário de Caratinga, Minas Gerais, 2006. 
BESEN, G. R.; RIBEIRO, H. Indicadores de sustentabilidade para programas municipais de coleta seletiva - métodos e técnicas de avaliação, São PauloRMSP, 2006.

BRASIL. Política Nacional de Resíduos Sólidos, Lei $\mathrm{n}^{\mathrm{o}} 12.305$, de 2 de agosto de 2010. Institui a Política Nacional de Resíduos Sólidos; altera a Lei no 9.605, de 12 de fevereiro de 1998; e dá outras providências. Disponível

em: $<$ http://www.planalto.gov.br/ccivil_03/_ato20072010/2010/lei/112305.htm>. Acessado em: 18/08/15.

ECO-UNIFESP. Princípio dos três 3 R's. Disponível em: http://dgi.unifesp.br/ecounifesp/index.php?option=co $\mathrm{m} \_$content $\&$ view $=$ article $\&$ id $=10 \&$ Itemid $=8>$. Acesso em: novembro de 2015 .

GÜNTHER, W. M. R.; BESEN, G.R.; JACOBI, P.R.; RIBEIRO, H.; VIVEIROS, M. Construção de indicadores de sustentabilidade de programas municipais de coleta seletiva e organizações de catadores - desafios conceituais e metodológicos. In: $24^{\circ}$ Congresso Brasileiro de Engenharia Sanitária e Ambiental, 2007, Belo Horizonte. Anais do $24^{\circ}$ Congresso Brasileiro de Engenharia Sanitária e Ambiental. Belo Horizonte: ABES -Associação Brasileira de Engenharia Sanitária e Ambiental, 2007. v. único. p. 1-8.

PORTO, M. F. Saúde do Trabalhador e o desafio ambiental: contribuições do enfoque ecossocial, da ecologiapolítica e do movimento pela justiça ambiental. Ciência e Saúde Coletiva. v. 10, n. 4, p. 111, out/dez. 2005.

ROCHA, J. M. Sustentabilidade em questão: Economia, sociedade e meio ambiente. Paco Editorial:2011.
RESOLUÇÃO CONAMA no 275 , de 25 de abril de 2001. Estabelece o código de cores para os diferentes tipos de resíduos, a ser adotado na identificação de coletores e transportadores, bem como nas campanhas informativas para a coleta seletiva. Disponível em: < http://www.mma.gov.br/port/conama/legiabre.cfm?co dlegi $=273>$. Acesso em novembro de 2015.

ROBEIRO, H.; BESEN, G.R. Panorama da coleta seletiva no Brasil: desafios e perspectivas a partir de três estudos de caso. InterfacEHS, v.2,p. 1-6, 2007.

$<$

